\title{
Striving in Style
}

Kenisha Coy

Continually learn, know ourselves in this polarized world, hidden truths, we felt you. On the wings of ancestral love, Michelle Obama arrived, our Modern Moses

Ride On, from gross, ignorant bell tolls telled, Beauty and intellect, shade to shame us, decadent hips and lips, Our Former First reminded us to treat our temple well.

Humility high, fist bumps on the low Heights like Dorothy, male dominated stigmas shattered, family first mattered. Designed like Ben Banneker type of flow. Letting Our Girls Learn, you encouraged us. Stay the course, Love rules and overshadows. Michelle, we're grateful and you will be missed.

K. Coy $(\Delta)$

My CARE Initiative, Fitzburg, MA, USA

(C) The Author(s) 2018

M. Duster et al. (eds.), Michelle Obama's Impact on African American Women and Girls, https://doi.org/10.1007/978-3-319-92468-7_15 